Article

\title{
Nanocellulose and Polycaprolactone Nanospun Composite Membranes and Their Potential for the Removal of Pollutants from Water
}

\author{
Hasbleidy Palacios Hinestroza ${ }^{1}$, Hilary Urena-Saborio ${ }^{2}$, Florentina Zurita ${ }^{3}$, \\ Aida Alejandra Guerrero de León ${ }^{1}$, Gunasekaran Sundaram ${ }^{2}$ and Belkis Sulbarán-Rangel 1,*(D) \\ 1 Department of Water and Energy, University of Guadalajara Campus Tonalá, Tonalá 45425, Mexico; \\ hasble27@yahoo.es (H.P.H.); aida.guerrero@academico.udg.mx (A.A.G.d.L.) \\ 2 Food and Bioprocess Engineering Lab, Department of Biological Systems Engineering, University of \\ Wisconsin, Madison, WI 53706, USA; hurena@wisc.edu (H.U.-S.); guna@wisc.edu (G.S.) \\ 3 Quality Environmental Laboratory, University of Guadalajara Campus Ciénega, Ocotlán 47829, Mexico; \\ fzurita@cuci.udg.mx \\ * Correspondence: Belkis.sulbaran@academicos.udg.mx; Tel.: +52-3320002300
}

Academic Editor: Ming-Chung Wu

Received: 14 December 2019; Accepted: 1 February 2020; Published: 6 February 2020

\begin{abstract}
A composite membrane based on polycaprolactone (PCL) and cellulose nanofibers (CNF) with different compositions was prepared using the electro-spinning method, with the objective of developing organic membranes with good mechanical properties to remove contaminants from water. Water is a resource of primary importance for life and human activities. In this sense, cellulose obtained from agave bagasse and polycaprolactone nanofibers was used to prepare membranes that were tested by filtering tap water. The membranes obtained presented a porosity and structure on a nanometric scale. The water quality variables evaluated after filtration with the PCL/CNF membranes showed $100 \%$ turbidity removal, $100 \%$ conductivity, and heavy metal removal of the order of $75 \%$ to 99\% for iron and chromium. CNF comprises biowaste derived from tequila production, and it has added value. Electro-spun CNF and PCL membranes can be applied as a "green" and eco-friendly filtration system for water purification.
\end{abstract}

Keywords: agave bagasse; cellulose nanofibers; membranes; electro-spinning; water filtration

\section{Introduction}

The World Health Organization (WHO), in collaboration with the United Nations Educational, Scientific and Cultural Organization (UNESCO), has established water and sanitation as being integral components in the sustainable development agenda [1]. It was decreed that the availability of water resources must be guaranteed in the decades to come, since they are key to guaranteeing life on Earth [2,3]. Tap water must meet regulatory standards for consumption; however, in countries such as Mexico, this does not happen [4]. This is because they do not have the necessary infrastructure for purification of the water that comes out of taps in homes; tap water can contain some pollutants. In addition, in some places, the pipes that transport water to homes are in poor condition and contain metal, discoloration, or chemical contaminants in the distribution system [5]. For this reason, the development of new organic/green technologies that allow the elimination of pollutants in tap water has become very important. This has led to efforts in developing nanostructural membranes for potential applications in water treatment [6].

Agave bagasse is an abundant source of lignocellulosic biomass [7-10], produced mainly in the state of Jalisco, Mexico. This solid, fibrous by-product is obtained after grinding and extracting the fermentable sugars from agave pineapples during tequila production [10]. This biomass represents 
about $40 \%$ (wet basis) of over 1000 tons of agave grown in Mexico [11]. The availability of such large quantities of agave bagasse [9] poses serious disposal problems, since most of the biomass ends up in clandestine dumps (due to little environmental regulation), causing adverse effects on the fertility of farmland [12], contamination by leachates, and phytosanitary risks due to the inadequate incorporation of this material into the soil [13]. Chemically, agave bagasse is $44.5 \%$ cellulose, $25.3 \%$ hemicellulose, and 20.1\% lignin [7]. Taking advantage of these constituents, there have been many efforts to use agave bagasse for various applications, e.g., the production of biopolymers [14,15], composting [16], animal nutrition [17], generation of biofuels [10,18], reinforcement materials [19], etc. More recently, agave bagasse is being explored for the production of cellulose nanofibers and nanocrystals $[7,8,20,21]$ to further diversify the utilization of this biowaste. On the other hand, electro-spinning of biopolymers has become popular in the manufacture of nanofibers for a variety of added value applications, such as tissue engineering, drug release, sensors, and air and liquid filtration systems [22-26].

Our main interest in electro-spinning agave cellulose nanofibers was to produce membranes that can retain suspended particles in water (due to the diameter of the fibers), a membrane with high porosity and good surface area properties. However, the main challenge with the preparation of electro-spun agave cellulose was the poor solubility of cellulose that was to be dispersed into an electro-spinnable liquid [24]. We overcame the poor solubility challenge by dissolving agave cellulose in dimethylformamide (DMF) and blending with polycaprolactone to prepare a composite electro-spun blend, subsequently producing electro-spun nanocellulose and polycaprolactone membranes. The main objective of using a copolymer blend was to improve technical properties, such as contaminant retention capacity, thermal stability, mechanical resistance, and chemical properties [24]. In this way, cellulose and polycaprolactone composites allow the preparation of a green and eco-friendly material from agave biowaste for its use in filtration systems. To date, the production of electro-spun agave cellulose and polycaprolactone nanofiber membranes has not yet been reported in literature. We then prepared electro-spun nanofibers of agave cellulose and polycaprolactone to produce membranes for water filtration.

On the other hand, domestic water filtration systems are widely used throughout the world, since they are very effective. These household filter systems consist of placing a filter at the tap outlet and using the water pressure that comes out of the pipe [26-28]. These filters are made of a variety of different materials, such as ceramics, activated carbon, and synthetic polymers [26]. Such materials are not biodegradable and generate another residue in the environment [27]. Therefore, the objective of this research is to prepare electro-spun, organic membranes from agave bagasse and polycaprolactone that have the ability to be used in the process of the filtration of tap water. The membranes can be used for selective contaminants (such as heavy metals in a colloidal state) and also reduce turbidity and conductivity of the water used for human consumption. It has been reported that cellulose and nanocellulose are effective in the adsorption of metals, such as cadmium, nickel, and silver, due to its negative surface charge [29]. In addition, the crystallinity and surface area of the cellulose (at nanometer scale) are enhanced, and other properties of interest also increase. Composite materials of nanocellulose and other synthetic polymers have also been reported and are shown to adsorb other metals, such as iron, chromium, and cadmium [6,30], due to surface loading. It is expected that electro-spun agave bagasse and polycaprolactone membranes separate the solids according to their sizes and retain certain metal ions due to the negative surface charges in their functional groups [7].

\section{Results and Discussion}

\subsection{Characterization of the Electro-spun Agave Bagasse Membranes}

The SEM micrographs (Figure 1) show the morphology of electro-spun nanofibers constituting the membranes. In general, all the membranes showed high porosity and pore interconnectivity, which could promote the filtration of water and adsorption of contaminants. 


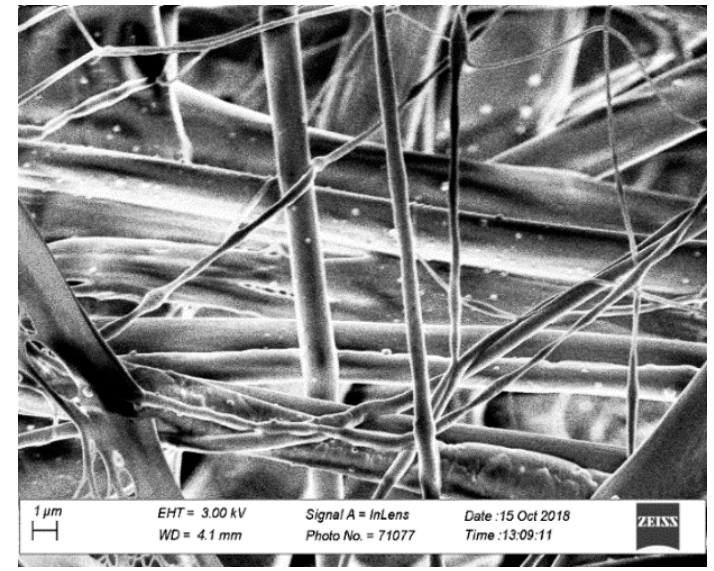

(a)

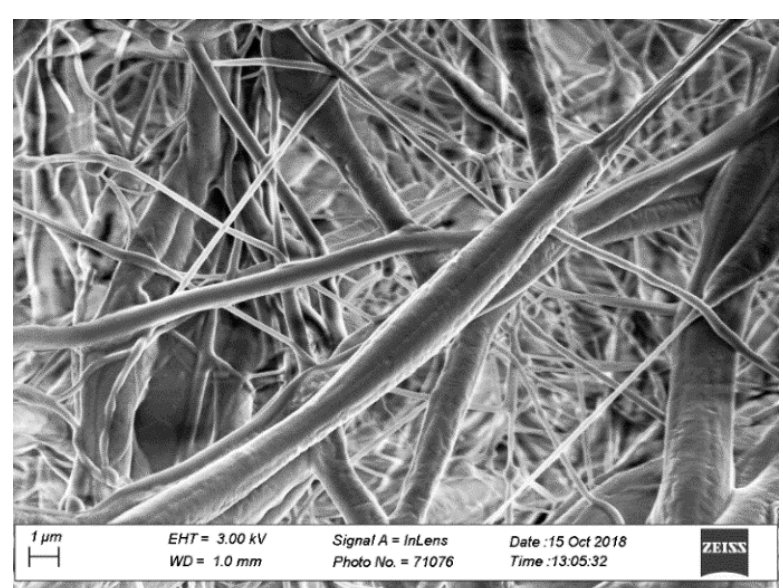

(b)

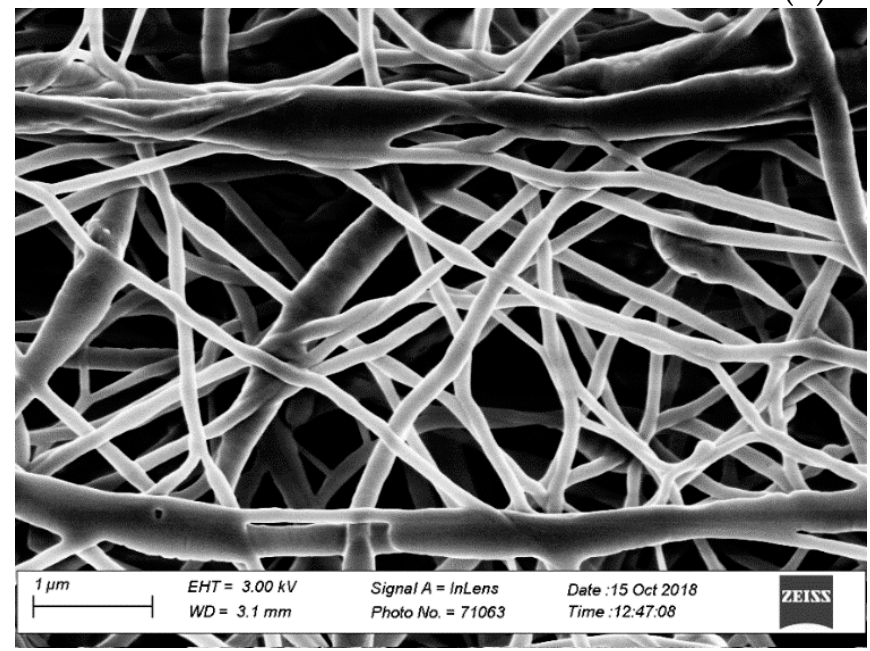

(c)

Figure 1. SEM images of electro-spun nanofibrous membranes fabricated from polycaprolactone/ cellulose nanofiber (PCL/CNF) copolymer blends at (v/v) ratios: (a) 80:20, (b) 60:40, and (c) 50:50.

The average diameter of electro-spun nanofibers is affected by the composition of the PCL/CNF blend used for electro-spinning (Table 1). The average (min, max) diameter of the electro-spun nanofibers formed with PCL80:CNF20, PCL60:CNF40, and PCL50:CNF50 blends were $1049 \mathrm{~nm}$ $(150 \mathrm{~nm}, 2000 \mathrm{~nm}) ; 1747 \mathrm{~nm}(120 \mathrm{~nm}, 3500 \mathrm{~nm})$; and $216 \mathrm{~nm}(40 \mathrm{~nm}, 250 \mathrm{~nm})$, respectively. This suggests that the incorporation of higher percentages of PCL (60\% and 80\%) may increase the viscosity of the copolymer blend, which, in turn, tends to increase the average diameters of the electro-spun nanofibers [31-33]. Table 1 also shows the porosity and permeability values of the membranes, which depends on the morphology of the fibers and the interconnection between them. The membrane of PCL80:CNF20 is more permeable than PCL60:NFC40 and PCL50:NFC50. Permeability is the ability of the membrane to allow a flow through the pores of its structure over a given time, and it is an important feature of the filtration process. The PCL60:CNF40 and PCL50:CNF50 membranes had the same permeability but different porosity. By having fibers of a nanometric scale, the PCL50:CNF50 membrane has pores that are smaller than the other membranes. In comparison to commercial cellulose membranes, they have greater permeability and porosity.

Another important aspect of contaminant retention is the functional groups that may be present in the membranes, because these could interact with the contaminants. FTIR analysis was performed for the membranes, and the FTIR spectroscopy data (Figure 2) showed absorbance intensities at 3335, $2895,1495,1140,1060$, and $905 \mathrm{~cm}^{-1}$ for the CNF starting material; these are associated with pure cellulose [34]. The adsorption at $3335 \mathrm{~cm}^{-1}$ is due to the stretching of hydroxyl groups $(\mathrm{OH})$ and, at 
$2895 \mathrm{~cm}^{-1}$, is due to $\mathrm{C}-\mathrm{H}$ stretching. The peaks at 1140 and $1060 \mathrm{~cm}^{-1}$ are attributed to $\mathrm{C}=\mathrm{O}, \mathrm{C}-\mathrm{C}$, and $\mathrm{C}-\mathrm{O}$ groups, and the peaks at $905 \mathrm{~cm}^{-1}$ correspond to $\mathrm{C}-\mathrm{O}-\mathrm{C}$ bending [7].

Table 1. Morphology of electro-spun nanofibers constituting the membranes. PCL = polycaprolactone and $\mathrm{CNF}=$ cellulose nanofiber.

\begin{tabular}{lccc}
\hline \multicolumn{1}{c}{ Membrane } & Fiber Diameter $(\mathbf{n m})$ & Permeability $(\boldsymbol{\mu m} / \mathbf{P a} / \mathbf{s})$ & Porosity \\
\hline PCL80:CNF20 & $1049 \pm 98$ & $0.635 \pm 0.01$ & $0.455 \pm 0.03$ \\
PCL60:CNF40 & $1747 \pm 153$ & $0.317 \pm 0.02$ & $0.468 \pm 0.02$ \\
PCL50:CNF50 & $216 \pm 12$ & $0.317 \pm 0.04$ & $0.302 \pm 0.05$ \\
Commercial cellulose membrane & $938 \pm 20$ & $1.270 \pm 0.04$ & $0.592 \pm 0.01$ \\
\hline
\end{tabular}

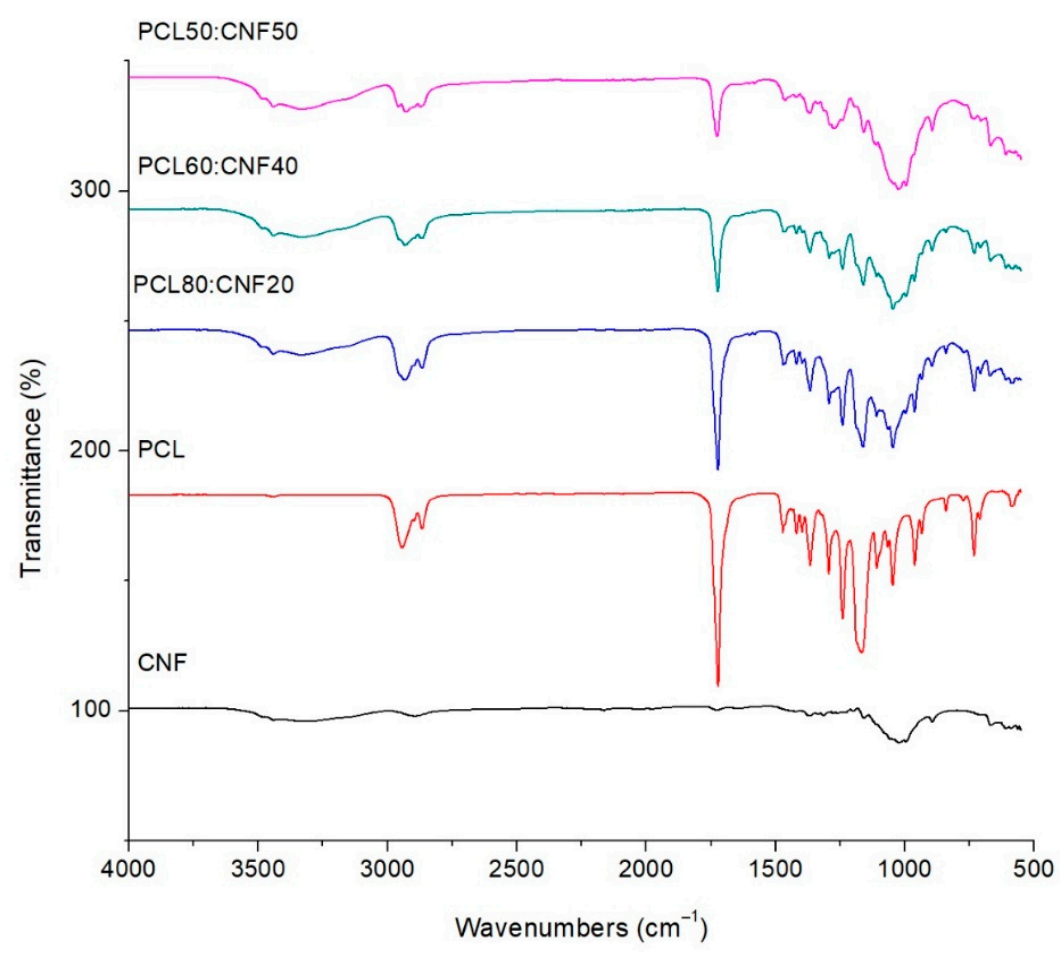

Figure 2. FTIR spectra of cellulose nanofibers (CNF), polycaprolactone (PCL), and electro-spun membranes for 50:50, 60:40, and 80:20 PCL/CNF $(v / v)$ ratios.

In the PCL spectrum (Figure 2), we can easily identify strong bands, such as carbonyl $(\mathrm{C}=\mathrm{O})$, stretching around $1723 \mathrm{~cm}^{-1}$. The peaks at 2954 and $2859 \mathrm{~cm}^{-1}$ correspond to the asymmetric and symmetric $\mathrm{CH}_{2}$ stretching. The bands at 1473,1243 , and $1176 \mathrm{~cm}^{-1}$ are related to the $\mathrm{C}-\mathrm{C}$ bending, asymmetric $\mathrm{C}-\mathrm{O}-\mathrm{C}$ stretching, and symmetric $\mathrm{C}-\mathrm{O}-\mathrm{C}$ stretching. The band at $1291 \mathrm{~cm}^{-1}$ corresponds to $\mathrm{C}-\mathrm{O}$ and $\mathrm{C}-\mathrm{C}$ stretching in the crystalline phase, and the band at $1157 \mathrm{~cm}^{-1}$ corresponds to $\mathrm{C}-\mathrm{O}$ and $\mathrm{C}-\mathrm{C}$ stretching in the amorphous phase [34]. In the spectrum of the PCL/CNF composite membranes, the characteristic peak for PCL at $1723 \mathrm{~cm}^{-1}$ shows a decrease in the intensity function to the CNF added to the copolymer blend, which suggests a decrease of the carbonyl group. Similarly, the pronounced signal at $3335 \mathrm{~cm}^{-1}$, corresponding to the $\mathrm{OH}$ groups present in CNF, seems to increase its intensity as the CNF content increases in the copolymer blend with PCL. Each membrane that includes cellulose fiber contains reactive $\mathrm{OH}$ groups, which could generate hydrogen bonds. Hydrogen bonding plays an important role in the adsorption process for the specific bonding that originates on the bonding sites of the composites [29].

The accessibility of the $\mathrm{OH}$ groups on the surface of the membranes is affected by the degree of crystallinity of the composite. According to this, the degree of crystallinity was measured and the crystalline planes of the membranes determined by XRD. The XRD spectrum (Figure 3) showed 
characteristic 2 theta peaks for PCL at $21.5^{\circ}$ and $23.8^{\circ}$, corresponding to the planes (110) and (200), respectively. This is due to the semi-crystalline structure of PCL [34]. Similarly, the spectrum of CNF shows a maximum 2 theta peak at $25^{\circ}$, corresponding to the (101) plane. On the other hand, the spectra of PCL/CNF electro-spun membranes showed a composition with a decrease in the intensity of the peaks at $25^{\circ}, 23.8^{\circ}$, and $21.5^{\circ}$, which directly correlated to the increase in CNF content. The crystallinity percentages calculated from the XRD spectra of CNF and PCL/CNF membranes correspond to $68.5 \%$ and $71.7 \%$, respectively [8].

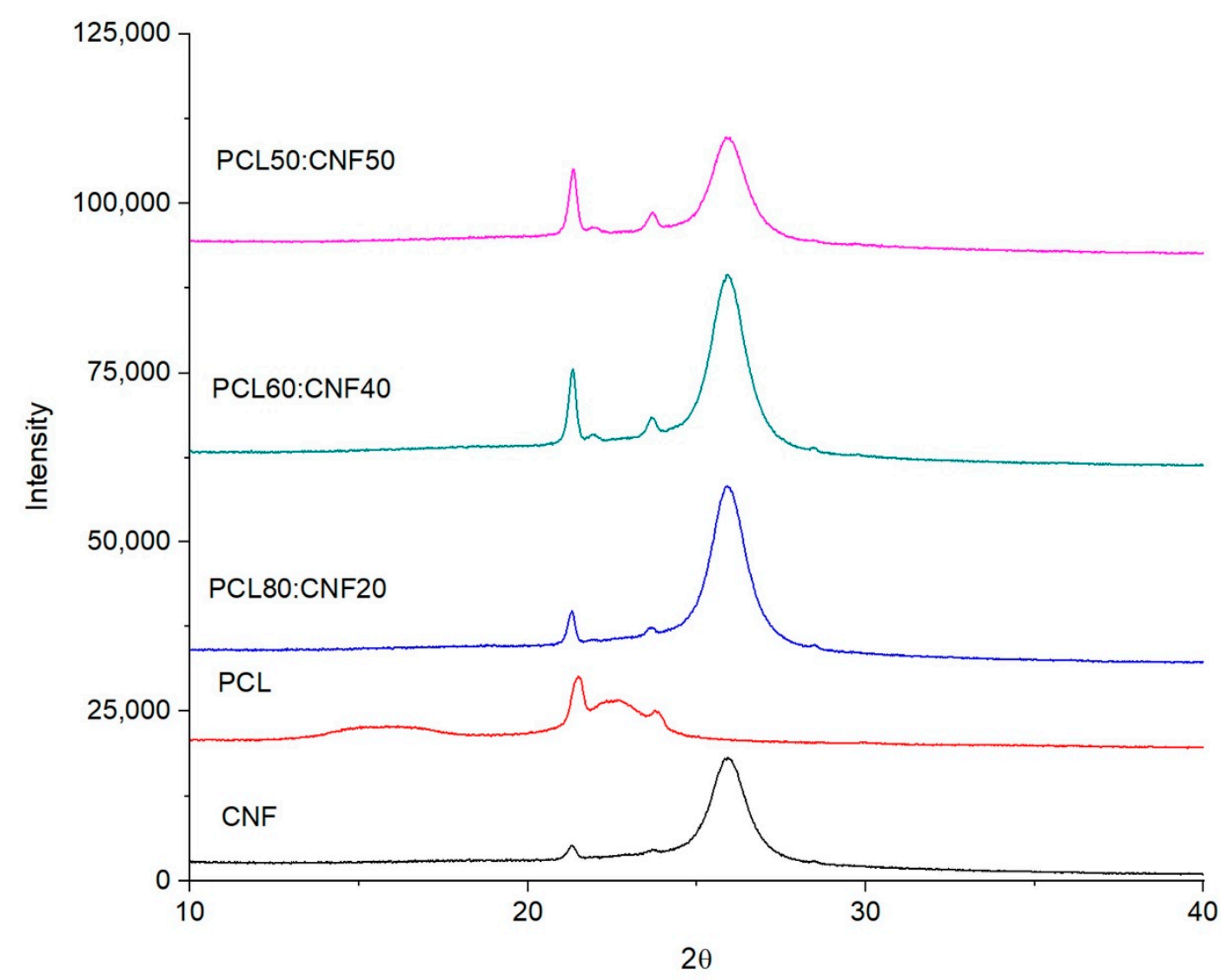

Figure 3. XRD spectra of cellulose nanofibers (CNF), polycaprolactone (PCL), and electro-spun membranes of 50:50, 60:40, and 80:20 PCL/CNF $(v / v)$ ratios.

Thermogravimetric analysis (TGA) was performed to investigate the thermostability of the $\mathrm{PCL} / \mathrm{CNF}$ membranes in comparison to those of CNF and PLC. Figure 4 shows that a major weight loss occurs between 200 and $400^{\circ} \mathrm{C}$ in the PCL/CNF membranes. The remnant weight percentage for the single PCL and CNF was about 5\% and 25\%, respectively. Initially, the TG curves for CNF show a small drop between 50 and $100{ }^{\circ} \mathrm{C}$, which corresponds to a mass loss of approximately $5 \%$, due to the moisture absorbed. Then, there was a weight loss event at approximately $343{ }^{\circ} \mathrm{C}$, corresponding to a $78 \%$ weight loss that can be attributed to the depolymerization of CNF. PCL and PCL/CNF membranes exhibited similar thermal degradation profiles, showing a loss of mass in the range of 200 to $430{ }^{\circ} \mathrm{C}$. This event was ascribed to polymer chain decomposition. The thermal stability of all the samples was analyzed by comparing the $10 \%$ (T10) and 50\% (T50) weight-loss temperatures. The T10 and T50 of PCL started at 358 and $390^{\circ} \mathrm{C}$, respectively, while all CNF showed higher T10 (341 $)$ and T50 $\left(503^{\circ}\right)$ values. The addition of PCL50:CNF50 increased the thermal stability of the PCL to $380^{\circ}$ and $429^{\circ} \mathrm{C}$ for T10 and T50, respectively (see the DTG curve, Figure $4 \mathrm{~b}$ ). This behavior can be attributed to the interaction between the interface of $\mathrm{CNF}$ and PCL, which increases the interaction between the polymer chains; this is in agreement with previous studies reported in the literature [35]. 


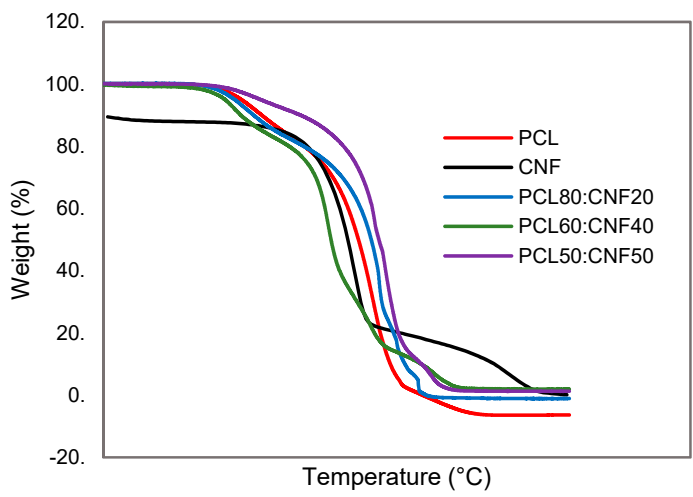

(a)

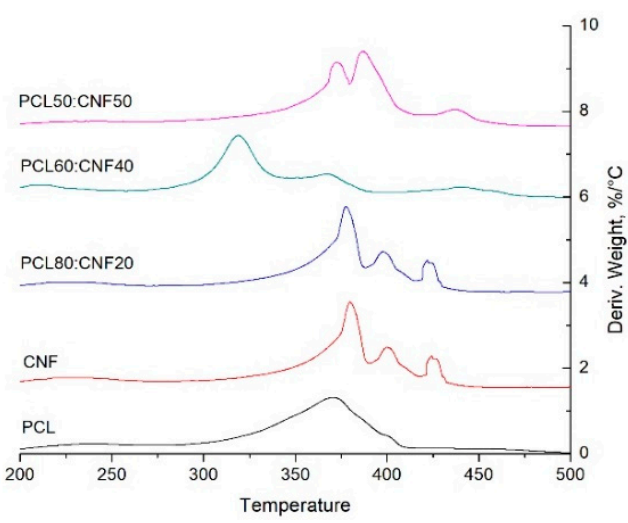

(b)

Figure 4. Thermogravimetric analysis: (a) TGA curves of cellulose nanofibers (CNF), polycaprolactone (PCL), and electro-spun membranes of 50:50, 60:40, and 80:20 PCL/CNF (v/v) ratios. (b) DTG curves of cellulose nanofibers (CNF), polycaprolactone (PCL), and electro-spun membranes of 50:50, 60:40, and 80:20 PCL/CNF $(v / v)$ ratios.

The mechanical properties of the electro-spun membranes are important for their uses in water filtration, since they must withstand the pressure exerted by flowing water. The typical stress-strain curves of PCL and PCL/CNF composite, electro-spun membranes, are shown in Figure 5. It was observed that in electro-spun membranes with the mixture of PCL/CNF at 80:20 and 60:40, the lowest elongation break values $(0.21$ and $0.30 \mathrm{~mm} / \mathrm{mm})$ were presented, respectively. The electro-spun membranes of pure PCL presented a greater elongation break value $(0.36 \mathrm{~mm} / \mathrm{mm})$. The decrease in elongation at the point of rupture that was observed in the mixtures of PCL: NFC at 80:20 and 60:40 can be attributed to a low interaction between PCL and NFC, which is usually indicative of the immiscibility between components in the mixture when the pure polymer is used [36]. However, PCL/CNF (50:50) composite membrane showed the highest elastic modulus and tensile strength $(0.58 \mathrm{~mm} / \mathrm{mm})$ of the three membrane systems that were fabricated. The increase in the elastic modulus and tensile strength could be due to a more effective interaction between CNF and PCL in the composite blend, resulting in an enhanced stiffness of the biomaterial.

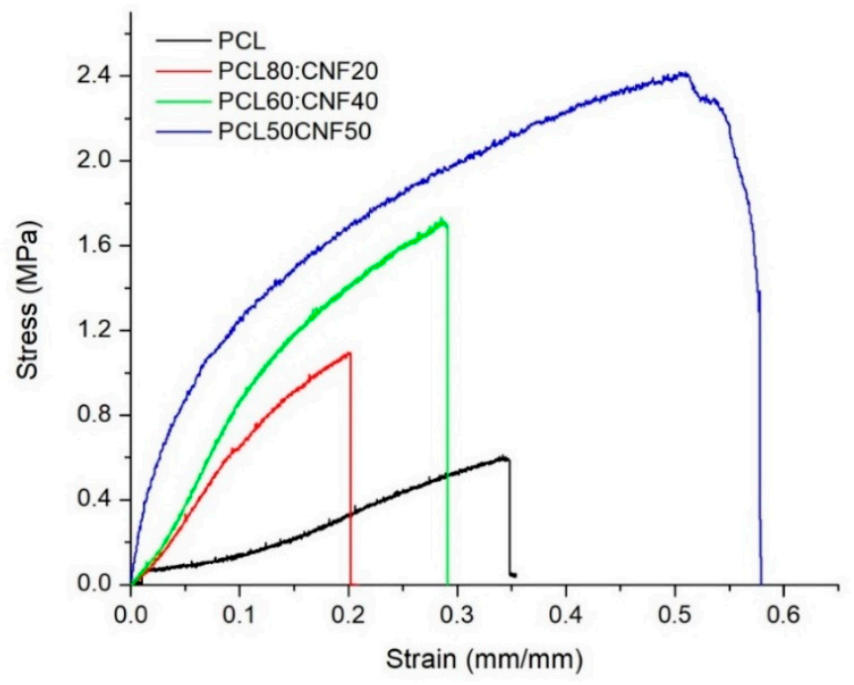

Figure 5. Stress-strain curves of polycaprolactone (PCL) and electro-spun membranes of 50:50, 60:40, and 80:20 PCL/CNF $(v / v)$ ratios. 


\subsection{Filtration Performance of the PCL:CNF Composite Electro-spun Membranes}

The filtration performance of the CNF:PCL composite electro-spun membrane was tested using tap water. Tap water must meet regulatory standards for consumption; however, in some places, the pipes that transport water to homes are in poor condition, introducing metal, discoloration, or chemical contaminants into the distribution system. Tap water was analyzed before filtration to look at the types of pollution they contained. Using atomic absorption spectrophotometry, it was possible to determine the heavy metal content; we found concentrations of iron and chrome of 0.006675857 and 0.000432294 ppm, respectively. After filtration of the tap water with the electro-spun membranes composed of PCL and NFC, there was a decrease in the concentration of iron and chromium in the filtered water, as seen in Figure 6.

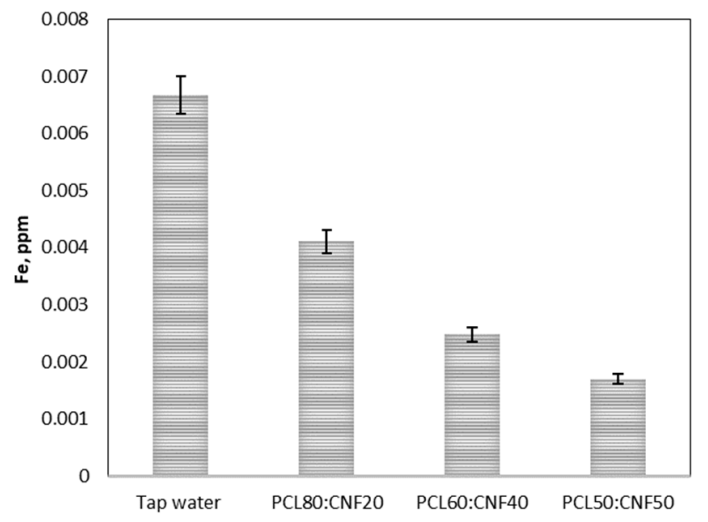

(a)

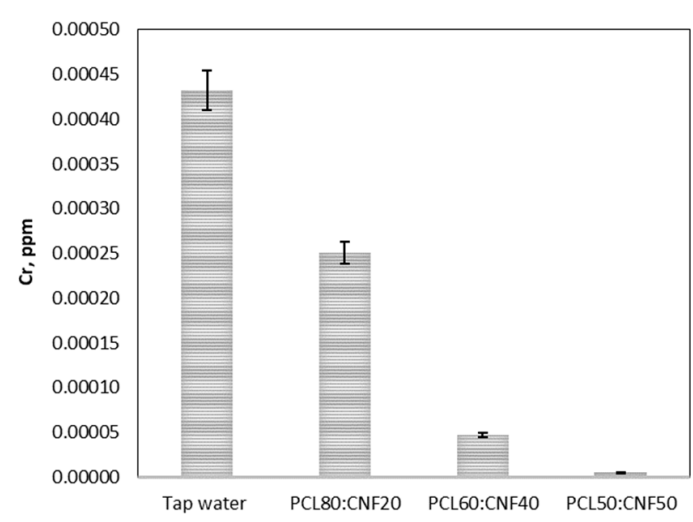

(b)

Figure 6. Removal of heavy metals in tap water using PCL/CNF $(v / v)$ ratio (80:20, 60:40, and 50:50) composite electro-spun membranes: (a) Iron (Fe) and (b) Chromium $(\mathrm{Cr})$.

If the reduction of heavy metals is analyzed in terms of percentage (Table 2), in the case of Fe, it was 38\%,62\%, and 75\% using the PCL80:CNF20, PCL60:CNF40, and PCL50:CNF50 membranes, respectively. Whereas, for $\mathrm{Cr}$, the removal percentage was higher, showing reductions of $42 \%, 90 \%$, and 99\% for the PCL80:CNF20, PCL60:CNF40, and PCL50:CNF50 membranes, respectively. The retention of these heavy metals by electro-spun membranes is mainly attributed to exclusion by pore size, since these metals were probably in colloidal form. Another reason for the retention could be explained by the interactions between the functional sites of the PCL and CNF electro-spun membrane surface with the heavy metal ions [36,37]. Hydrogen bonding played an important role in the adsorption process for the specific bonding that originates on the bonding sites of the composites, and, for that reason, the cellulose nanofibers were the active material in the composite because their surfaces possess different functional groups. Each unit of D-glucopyranoside within the cellulose chain contains three reactive $\mathrm{OH}$ groups, two secondaries $\left(\mathrm{OH}-\mathrm{C}_{2}\right.$ and $\left.\mathrm{OH}-\mathrm{C}_{3}\right)$, and one primary $\left(\mathrm{OH}-\mathrm{C}_{6}\right)$. These negative hydroxyl groups, present in cellulose nanofibers [7], were able to form bonding groups with the positively charged Fe and $\mathrm{Cr}$ metal ions [30,38]. This was observed in membranes with a higher percentage of cellulose nanofibers (PCL50:CNF50), where greater retention of heavy metals was obtained compared to membranes with a higher percentage of PCL (See Table 2).

The results of turbidity and conductivity tests are also shown in Table 2. According to the World Health Organization, turbidity is an extremely useful indicator of water quality, because it indicates the presence of suspended chemical and biological particles [39]. In drinking water, a value higher than 5 nephelometric turbidity units (NTUs) compromises water safety and its aesthetic appearance for consumers. Conductivity is also important, as it is routinely used in many industrial and environmental applications as a fast, cheap, and reliable way to measure ionic content in a solution and is directly linked to the amount of total dissolved solids. According to the results, both turbidity and conductivity were reduced considerably (by almost 100\% in both cases) by all of the composite PCL/CNF electro-spun 
membrane systems. This is explained by the fact that the contaminant particles in the tap water are of a larger size than the porous structures of the membranes and, therefore, are easily retained by their pores.

Table 2. Reduction of turbidity, conductivity, and heavy metal content (iron and chromium) in tap water before and after filtration.

\begin{tabular}{ccccccc}
\hline \multirow{2}{*}{ Membrane } & \multicolumn{2}{c}{ Turbidity (NTU) } & \multicolumn{2}{c}{ Conductivity (S/m) } & \multirow{2}{*}{$\begin{array}{c}\text { Iron } \\
\text { Reduction (\%) }\end{array}$} & $\begin{array}{c}\text { Chromium } \\
\text { Reduction (\%) }\end{array}$ \\
\cline { 2 - 5 } & Before & After & Before & After & & \\
\hline PCL80:CNF20 & $70 \pm 3.5$ & 0.91 & $669 \pm 3.5$ & 0 & $38 \pm 1.9$ & $42 \pm 2.1$ \\
PCL60:CNF40 & $83 \pm 4.1$ & 0.00 & $669 \pm 3.5$ & 0 & $62 \pm 3.1$ & $90 \pm 4.5$ \\
PCL50:CNF50 & $83 \pm 4.1$ & 0.00 & $669 \pm 3.5$ & 0 & $75 \pm 3.5$ & $99 \pm 3.5$ \\
\hline
\end{tabular}

SEM was used to analyze the membrane surfaces after filtration. As shown in Figure 7, the contaminating particles present in tap water were adhered to the PCL/CNF electro-spun membranes. In the case of the membrane comprising the PCL80:CNF20 blend, Figure 7a shows areas that are free of contaminating particles; this may be due to the pore size of the membrane being significantly larger than the particle diameter. This could also be related to its lower efficiency in removing heavy metals, as shown in Figure 6.

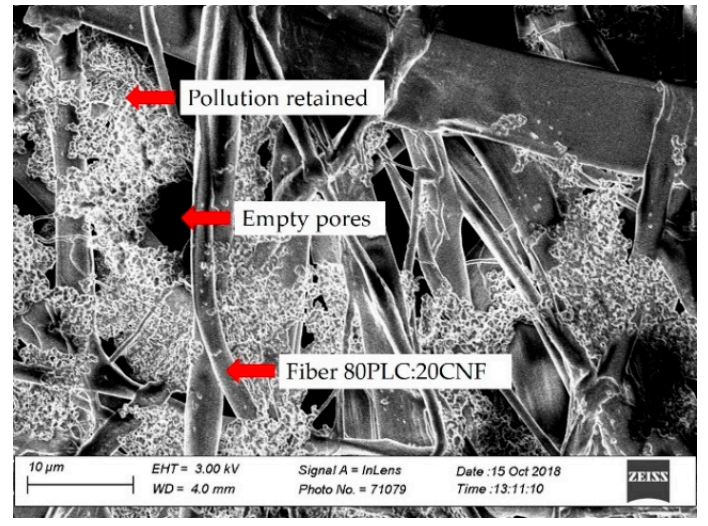

(a)

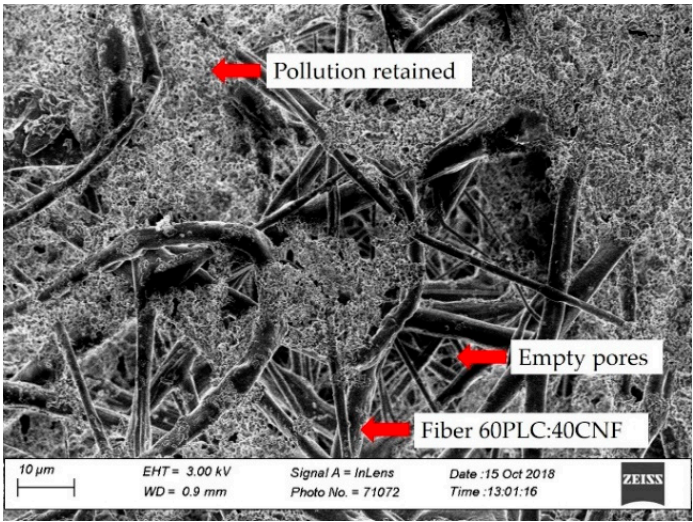

(b)

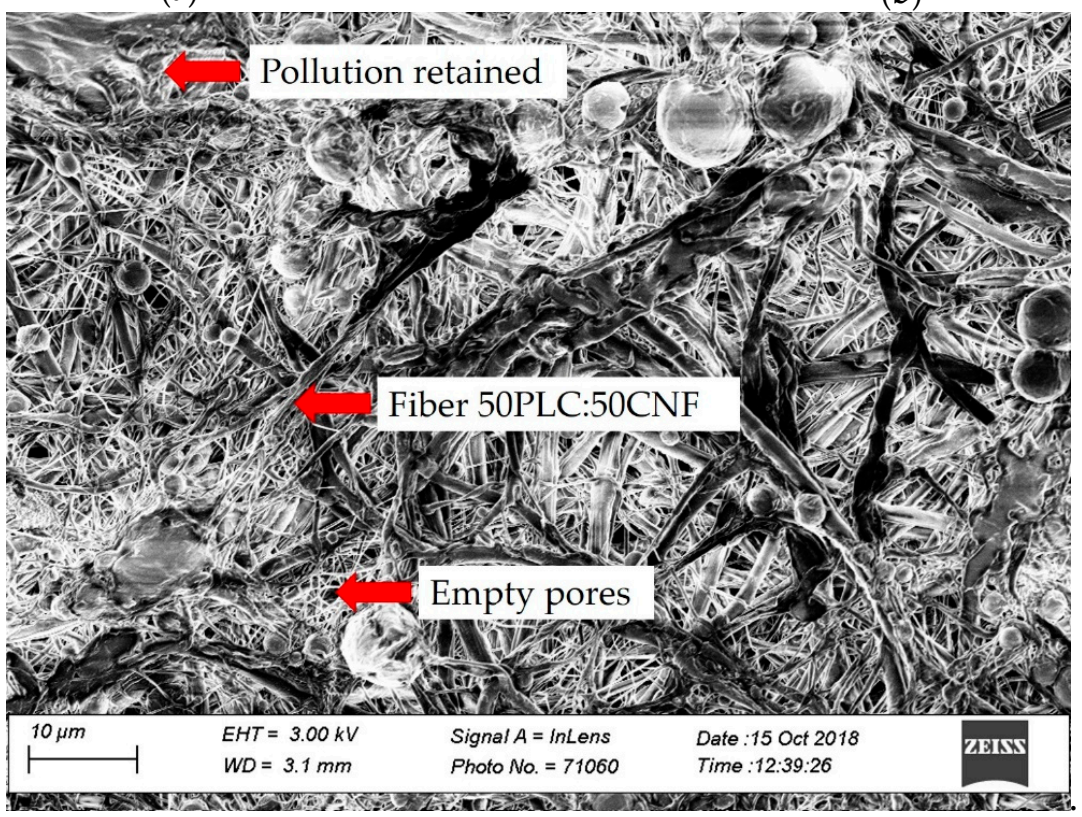

(c)

Figure 7. SEM images after filtration of tap water using electro-spun membranes of PCL: CNF $(v / v)$ ratios: (a) 80:20, (b) 60:40, and (c) 50:50. 
In the case of the PCL/CNF (60:40) membrane (Figure 7b), it also shows zones that are free of contaminating particles; they can be seen to have been adsorbed but in a smaller proportion. On the other hand, the contaminating particles fully cover the PCl/CNF (50:50) membrane surface (Figure 7c), showing the best results for removal of heavy metals and greater resistance to tension. Therefore, they are a suitable candidate for use in a filtration system for the purification of contaminated water.

\section{Materials and Methods}

Polycaprolactone (molecular weight $=80,000$, GPC and melt viscosity ASTM D1238:73); $N$-dimethylformamide (DMF) (anhydrous, 99.8\% $w / v)$; and chloroform $(99.8 \% w / v)$ were purchased from Sigma-Aldrich (St. Louis, MO, USA) [40]. Cellulose and nanofiber fibers (CNF) were obtained according to the methodology described in a previous work [7]. In summary, the agave bagasse fibers of the Agave tequilana Weber Plant (Arenal Jalisco, Mexico) were delignified, degreased, and cut, and the cellulose was then obtained using the organosolv method. The cellulose pulp was then bleached. Subsequently, agave cellulose fibers were processed at $1.5 \%$ consistency in an M-110P microfluidizer and, thus, fibrillation and CNF formation occurred.

The reagents used to determine the chemical composition were supplied by Sigma-Aldrich (Toluca, Mexico), i.e., aqueous solutions of acetic acid $\left(\mathrm{CH}_{3} \mathrm{COOH} 99 \% w / v\right)$; sodium chlorite $\left(\mathrm{NaClO}_{2}, 80 \%\right.$ $w / v)$; potassium hydroxide $(\mathrm{KOH}, 90 \% w / v)$; sodium hydroxide $(\mathrm{NaOH}, 97 \% w / v)$; and nitric acid $\left(\mathrm{H}_{3} \mathrm{NO}_{3}, 99.5 \% \mathrm{w} / \mathrm{v}\right)$. All chemicals were used without further purification.

\subsection{Preparation of Membranes by Electro-Spinning}

For the preparation of PCL/CNF composite membranes, $2 \mathrm{~g}$ of CNF was weighed with a consistency of $2.5 \% w / v$ and diluted in DMF. The solution was left in a shaker for $24 \mathrm{~h}$ and then placed in ultrasound for $30 \mathrm{~min}$, followed by mixing with PLC $(40 \% w / v)$ diluted in chloroform. Three types of membranes were prepared using different PCL:CNF ratios, i.e., 80:20, 50:50, and 60:40 (v/v).

The electro-spinning equipment was set up as follows: collector distance, $20 \mathrm{~cm}$; flow rate, $0.5 \mathrm{~mL} / \mathrm{h}$; and the voltage 15 to $20 \mathrm{kV}$ (GAMMA, High Voltage Research, FL, USA). The CNF/PCL composite blend was loaded into a $3 \mathrm{~mL}$ syringe with a stainless-steel needle and was injected and collected on a plate with a ground connection covered with aluminum foil. After $90 \mathrm{~min}$, the deposited fibers matted into an electro-spun membrane of $10 \times 8 \mathrm{~cm}$, which was stored in a dissector for subsequent characterization and use.

\subsection{Characterization of the Obtained Membranes}

The functional groups in the membranes were analyzed using Fourier transform-infrared (FT-IR) spectroscopy (Nicolet 4700 ATR FT-IR, Thermo Scientific, Grand Island, NY, USA). Sixteen scans were performed in the wavenumber range of 400 to $4400 \mathrm{~cm}^{-1}$ and at a resolution of $4 \mathrm{~cm}^{-1}$. The membrane crystallinity index was determined based on the empirical method of Segal [7], using X-ray diffraction spectroscopy (XRD; Empyrean, Siemens, Washington, DC, USA). To study the thermal degradation characteristics of the membranes, thermogravimetric analysis (TGA) was carried out (Q100, TA Instruments, Lindon, UT, USA) with heating and cooling rates of $20^{\circ} \mathrm{C} / \mathrm{min}$. A $5 \mathrm{mg}$ sample was heated to temperatures in the range of 50 to $400^{\circ} \mathrm{C}$ in a nitrogen-rich atmosphere. A flow rate of $20 \mathrm{~mL} / \mathrm{min}$ was used, and measurements were carried out in duplicate.

A scanning electron microscope (SEM; Leo 1530-FE, Zeiss, Cambridge, UK) was used to analyze the morphology of the membranes and the contaminant retention capacity. To perform these tests, images of the membranes were taken before and after filtration of contaminated water. The micrographs were obtained at an acceleration voltage of 15 and $20 \mathrm{kV}$ and an increased range of 1000X to 5000X. The ImageJ program was used to measure the diameter of the fiber and porosity area in the SEM image for each membrane [41]. The porosity calculation was according to Equation (1), where ve is the volume of empty spaces and $v$ is the total volume of the sample:

$$
\text { Porosity }=\frac{v e}{v}
$$


Tensile properties were measured on 0.5-mm-thick, 12-mm-wide, and 50-mm-long strips of the membranes using a universal testing machine (Instron 5967, 50-N load cell) at a crosshead speed of $5 \mathrm{~mm} / \mathrm{min}$. The measurements for each sample were carried out in triplicate. Young's modulus was calculated by dividing the tensile stress by the engineering extensional strain in the elastic (initial, linear) portion of the stress-strain curve. In the case of the electro-spun prepared membranes, their permeability was determined using the Tappi T460 and Gurley method [42], which is based on the time that a volume of air $(100 \mathrm{~mL})$ passes through the membrane at a determined and controlled pressure. A Gurley-Hill-type apparatus was used, and the results were expressed in seconds per $100 \mathrm{~mL}$. The calculated permeability was found by using Equation (2):

$$
P=\frac{1.27}{t}
$$

where $P$ is permeability $\mu \mathrm{m} / \mathrm{Pa} / \mathrm{s}$ and $t$ is time in seconds per $100 \mathrm{~mL}$.

\subsection{Filtration Performance of the PCL:CNF Composite Electro-Spun Membranes}

The PCL/CNF membranes were tested for their ability to filter tap water. The tap water was analyzed for certain water quality parameters before and after being filtered with the prepared membranes. The conductivity (Hach model HQ40d, Ocotlán, Jal, México); turbidity (HANNAH Instruments model HI 03703, Ocotlán, Jal, México); and heavy metal concentration atomic absorption spectrometry (ICP Perkin-Elmer-Optima 4300 DV, Madison, WI, USA) were measured. The initial characteristics of the tap water samples are shown in Table 3.

Table 3. Characteristics of the tap water used for testing filtration performance of the electro-spun membrane.

\begin{tabular}{ccccccc}
\hline \multirow{2}{*}{ pH } & \multirow{2}{*}{$\begin{array}{c}\text { Temperature } \\
\left({ }^{\circ} \mathbf{C}\right)\end{array}$} & \multirow{2}{*}{$\begin{array}{c}\text { Conductivity } \\
(\mu \mathrm{S} / \mathrm{cm})\end{array}$} & \multirow{2}{*}{$\begin{array}{c}\text { Turbidity } \\
(\mathbf{N T U})\end{array}$} & \multicolumn{3}{c}{ Heavy Metal Concentration (ppb) } \\
\cline { 5 - 7 } & & & Chlorine & Iron & Chromium \\
\hline $8.69 \pm 0.17$ & $27.5 \pm 0.5$ & $669 \pm 0.18$ & $81 \pm 1.62$ & $57.041 \pm 0.11$ & $6.676 \pm 0.13$ & $0.432 \pm 0.08$ \\
\hline
\end{tabular}

The filtration testing system apparatus consisted of a filtration Buchner funnel that contained the PCL/CNF membrane as a water filter. The funnel was mounted in a Kitasato flask and connected to a vacuum pump (WELCH 1HP, Ocotlán, Jal, México) with a pressure of 59,984.4 Pascal, as shown in Figure 8. The volume of tap water to be filtered was $100 \mathrm{~mL}$, and the time was $10 \mathrm{~s}$. The membranes had a diameter of $4 \mathrm{~cm}$ and a thickness of $0.25 \mathrm{~mm}$. After filtering the water, samples of the filtered water were taken and heavy metals, conductivity, and turbidity were measured. The membranes were dried at room temperature, and then SEM photographs were taken and the surface contaminants analyzed.

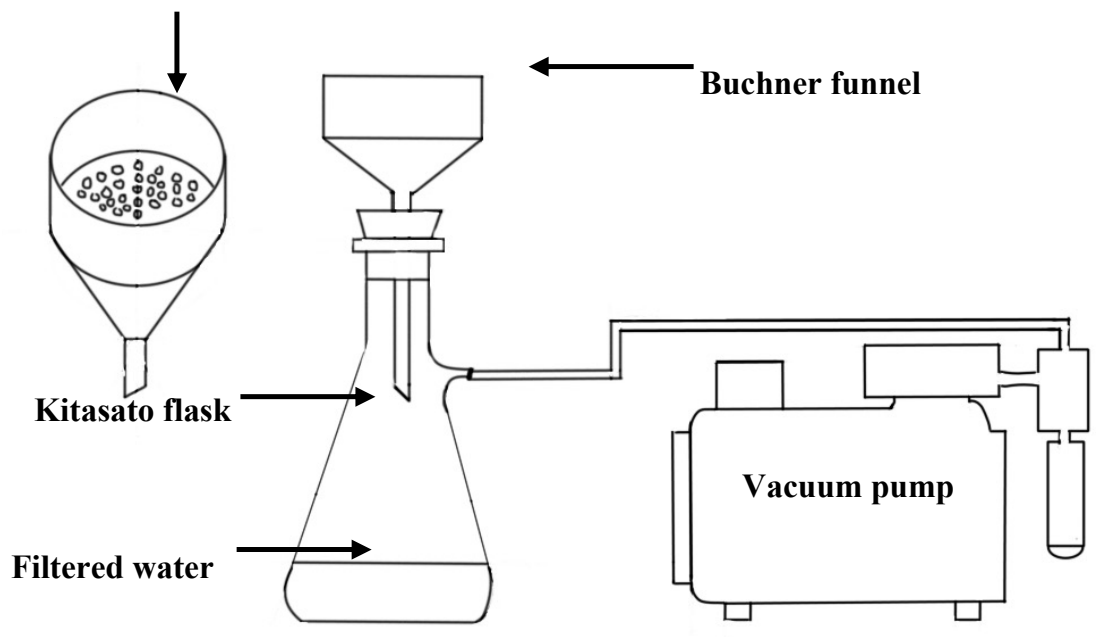

Figure 8. Apparatus used to evaluate water filtration performance of CNF/PCL membrane. 


\section{Conclusions}

Nanocellulose and polycaprolactone composite membranes were developed via electro-spinning. The results of the characterization of the PCL/CNF composite membrane showed a good compatibility between the CNF and PCL, since the mechanical properties of the composite biomaterial were higher, which is important in water filtration systems. Three membrane systems were compared in terms of their ability to improve water quality, in terms of turbidity, conductivity, and the removal of contaminating metals (iron and chromium). The differences found in these properties were interpreted with respect to the nanostructural morphology of the membranes and the interconnection between the composite nanofibers of PCL and CNF. The electro-spun PCL50:CNF50 membrane successfully retained heavy metals in tap water $(\mathrm{Fe}=75 \%$ and $\mathrm{Cr}=99 \%)$ and removed $100 \%$ turbidity and conductivity. The results showed that CNF is a suitable biowaste material derivative from tequila production, with an added value in the production of composite PCL/CNF electro-spun membranes that can be applied in eco-friendly filtration systems for water purification.

Author Contributions: Methodology and experimental work: H.P.H. and H.U.-S.; formal analysis: F.Z. and A.A.G.d.L.; writing - original draft preparation: H.P.H. and B.S.-R.; conceptualization and supervision: G.S. and B.S.-R. All authors have read and agreed to the published version of the manuscript.

Funding: This research received no external funding.

Acknowledgments: The authors are grateful to the National Council of Science and Technology México (CONACyT) for their financial support of student grants, as well as Ms. Janessa Grieve for providing help with the language in this document.

Conflicts of Interest: The authors declare no conflicts of interest.

\section{References}

1. United Nation Development Programme. Available online: https://www.undp.org/content/undp/en/home/ sustainable-development-goals.html (accessed on 14 December 2019).

2. Garcia-Alonso, J.A.; Zurita-Martinez, F.; Guzmán-González, C.A.; Del Real-Olvera, J.; Sulbarán-Rangel, B. Nanostructured diatomite and its potential for the removal of an antibiotic from water. Bioinspir. Biomimet. 2018, 7, 167-173. [CrossRef]

3. Tejeda, A.; Torres-Bojorges, A.X.; Zurita, F. Carbamazepine removal in three pilot-scale hybrid wetlands planted with ornamental species. Ecol. Eng. 2017, 98, 410-417. [CrossRef]

4. Bonilla-Lemus, P.; Ramírez-Bautista, G.A.; Zamora-Muñoz, C.; Ibarra-Montes, M.D.R.; Ramírez-Flores, E.; Hernández-Martínez, M.D. Acanthamoeba spp. in domestic tap water in houses of contact lens wearers in the metropolitan area of Mexico City. Exp. Parasitol. 2010, 126, 54-58. [CrossRef] [PubMed]

5. Park, H.; Choo, G.; Kim, H.; Oh, J.-E. Evaluation of the current contamination status of PFASs and OPFRs in South Korean tap water associated with its origin. Sci. Total Environ. 2018, 634, 1505-1512. [CrossRef]

6. Carpenter, A.W.; de Lannoy, C.-F.; Wiesner, M.R. Cellulose Nanomaterials in Water Treatment Technologies. Environ. Sci. Technol. 2015, 49, 5277-5287. [CrossRef]

7. Palacios, H.H.; Hernandez, D.J.A.; Esquivel, A.M.; Toriz, G.; Rojas, O.J.; Sulbaran-Rangel, B.C. Isolation and Characterization of Nanofibrillar Cellulose from Agave tequilana Weber Bagasse. Adv. Mater. Sci. Eng. 2019, 2019, 7. [CrossRef]

8. Hernández, J.A.; Romero, V.H.; Escalante, A.; Toriz, G.; Rojas, O.J.; Sulbarán, B. Agave tequilana Bagasse as Source of Cellulose Nanocrystals via Organosolv Treatment. BioResources 2018, 13, 3603-3614. [CrossRef]

9. Robles, E.; Fernández-Rodríguez, J.; Barbosa, A.M.; Gordobil, O.; Carreño, N.L.V.; Labidi, J. Production of cellulose nanoparticles from blue agave waste treated with environmentally friendly processes. Carbohydr. Polym. 2018, 183, 294-302. [CrossRef]

10. Alemán-Nava, G.S.; Gatti, I.A.; Parra-Saldivar, R.; Dallemand, J.-F.; Rittmann, B.E.; Iqbal, H.M.N. Biotechnological revalorization of Tequila waste and by-product streams for cleaner production-A review from bio-refinery perspective. J. Clean. Prod. 2018, 172, 3713-3720. [CrossRef]

11. National Regulator Council for Tequila Industry. Available online: https://www.crt.org.mx/ (accessed on 5 June 2019). 
12. Gobeille, A.; Yavitt, J.; Stalcup, P.; Valenzuela, A. Effects of soil management practices on soil fertility measurements on Agave tequilana plantations in Western Central Mexico. Soil Tillage Res. 2006, 87, 80-88. [CrossRef]

13. Rodríguez, R.; Jiménez, J.F.; del Real, J.I.; Salcedo, E.; Zamora, J.F.; Íñiguez, G. Utilización de subproductos de la industria tequilera. Parte 11. Compostaje de bagazo de agave crudo y biosólido provenientes de una planta de tratamiento de vinazas tequileras. Rev. Int. Contam. Ambient. 2013, 29, 303-313.

14. Torres-Tello, E.V.; Robledo-Ortíz, J.R.; González-García, Y.; Pérez-Fonseca, A.A.; Jasso-Gastinel, C.F.; Mendizábal, E. Effect of agave fiber content in the thermal and mechanical properties of green composites based on polyhydroxybutyrate or poly(hydroxybutyrate-co-hydroxyvalerate). Ind. Crops Prod. 2017, 99, 117-125. [CrossRef]

15. Langhorst, A.E.; Burkholder, J.; Long, J.; Thomas, R.; Kiziltas, A.; Mielewski, D. Blue-agave fiber-reinforced polypropylene composites for automotive applications. BioResources 2018, 13, 820-835. [CrossRef]

16. Íñiguez, G.; Valadez, A.; Manríquez, R.; Moreno, M.V. Utilization of by-products from the tequila industry. Part 10: Characterization of different decomposition stages of Agave tequilana webber bagasse using FTIR spectroscopy, thermogravimetric analysis and scanning electron microscopy. Rev. Int. Contam. Ambient. 2011, 27, 61-74.

17. Ramírez-Cortina, C.R.; Alonso-Gutiérrez, M.S.; Rigal, L. Valorización de residuos agroindustriales del tequila para alimentación de rumiantes. Rev. Chapingo Ser. Cienc. For. Ambiente 2012, 18, 449-457. [CrossRef]

18. Pérez-Pimienta, J.A.; Vargas-Tah, A.; López-Ortega, K.M.; Medina-López, Y.N.; Mendoza-Pérez, J.A.; Avila, S.; Singh, S.; Simmons, B.A.; Loaces, I.; Martinez, A. Sequential enzymatic saccharification and fermentation of ionic liquid and organosolv pretreated agave bagasse for ethanol production. Bioresour. Technol. 2017, 225, 191-198. [CrossRef]

19. Annandarajah, C.; Li, P.; Michel, M.; Chen, Y.; Jamshidi, R.; Kiziltas, A.; Hoch, R.; Grewell, D.; Montazami, R. Study of Agave Fiber-Reinforced Biocomposite Films. Materials 2019, 12, 99. [CrossRef]

20. Lomelí-Ramírez, M.G.; Valdez-Fausto, E.M.; Rentería-Urquiza, M.; Jiménez-Amezcua, R.M.; Anzaldo Hernández, J.; Torres-Rendon, J.G.; García Enriquez, S. Study of green nanocomposites based on corn starch and cellulose nanofibrils from Agave tequilana Weber. Carbohydr. Polym. 2018, 201, 9-19. [CrossRef]

21. Pech-Cohuo, S.-C.; Canche-Escamilla, G.; Valadez-González, A.; Fernández-Escamilla, V.V.A.; UribeCalderon, J. Production and Modification of Cellulose Nanocrystals from Agave tequilana Weber Waste and Its Effect on the Melt Rheology of PLA. Int. J. Polym. Sci. 2018, 2018. [CrossRef]

22. Urena-Saborio, H.; Alfaro-Viquez, E.; Esquivel-Alvarado, D.; Madrigal-Carballo, S.; Gunasekaran, S. Electrospun plant mucilage nanofibers as biocompatible scaffolds for cell proliferation. Int. J. Biol. Macromol. 2018, 115, 1218-1224. [CrossRef]

23. Tang, Y.; Chen, L.; Zhao, K.; Wu, Z.; Wang, Y.; Tan, Q. Fabrication of PLGA/HA (core)-collagen/amoxicillin (shell) nanofiber membranes through coaxial electrospinning for guided tissue regeneration. Compos. Sci. Technol. 2016, 125, 100-107. [CrossRef]

24. Yalcinkaya, F. Preparation of various nanofiber layers using wire electrospinning system. Arab. J. Chem. 2019, 12, 5162-5172. [CrossRef]

25. Hu, X.; Liu, S.; Zhou, G.; Huang, Y.; Xie, Z.; Jing, X. Electrospinning of polymeric nanofibers for drug delivery applications. J. Control. Release 2014, 185, 12-21. [CrossRef] [PubMed]

26. Hoslett, J.; Massara, T.; Malamis, S.; Ahmad, D.; van den Boogaert, I.; Katsou, E.; Ahmad, B.; Ghazal, H.; Simons, S.; Wrobel, L.; et al. Surface water filtration using granular media and membranes: A review. Sci. Total Environ. 2018, 639, 1268-1282. [CrossRef]

27. Molodkina, L.; Kolosova, D.; Leonova, E.; Kudoyarov, M.; Patrova, M.; Vedmetskii, Y. Track membranes in post-treatment of domestic wastewater. Pet. Chem. 2012, 52, 487-493. [CrossRef]

28. Goncharuk, V. Drinking Water: Factors Affecting the Quality of Drinking Water. In Drinking Water: Physics, Chemistry and Biology; Goncharuk, V.V., Ed.; Springer International Publishing: Cham, Switzerland, 2014; pp. 105-245.

29. Kardam, A.; Raj, K.R.; Srivastava, S.; Srivastava, M.M. Nanocellulose fibers for biosorption of cadmium, nickel, and lead ions from aqueous solution. Clean Technol. Environ. Policy 2014, 16, 385-392. [CrossRef]

30. Gomez-Maldonado, D.; Vega Erramuspe, I.; Peresin, M. Natural polymers as alternative adsorbents and treatment agents for water remediation. BioResourses 2019, 14, 10093-10160. [CrossRef] 
31. Pervez, N.M.; Stylios, K.G. An Experimental Approach to the Synthesis and Optimisation of a 'Green' Nanofibre. Nanomaterials 2018, 8, 383. [CrossRef]

32. Yalcinkaya, F.; Hruza, J. Effect of Laminating Pressure on Polymeric Multilayer Nanofibrous Membranes for Liquid Filtration. Nanomaterials 2018, 8, 272. [CrossRef]

33. Xu, Z.; Zhao, R.; Huang, X.; Wang, X.; Tang, S. Fabrication and biocompatibility of agarose acetate nanofibrous membrane by electrospinning. Carbohydr. Polym. 2018, 197, 237-245. [CrossRef]

34. Elzein, T.; Nasser-Eddine, M.; Delaite, C.; Bistac, S.; Dumas, P. FTIR study of polycaprolactone chain organization at interfaces. J. Colloid Interface Sci. 2004, 273, 381-387. [CrossRef] [PubMed]

35. Correa, E.; Moncada, M.E.; Zapata, V.H. Electrical characterization of an ionic conductivity polymer electrolyte based on polycaprolactone and silver nitrate for medical applications. Mater. Lett. 2017, 205, 155-157. [CrossRef]

36. Hamad, A.; Hassouna, M.; Shalaby, T.; Elkady, M.; Abd Elkawi, M.; Hamad, H. Electrospun cellulose acetate nanofiber incorporated with hydroxyapatite for removal of heavy metals. Int. J. Biol. Macromol. 2019. [CrossRef]

37. Hamad, H.; Abd El-latif, M.; Kashyout, A.; Sadik, W.; Feteha, M. Optimizing the preparation parameters of mesoporous nanocrystalline titania and its photocatalytic activity in water: Physical properties and growth mechanisms. Process Saf. Environ. Prot. 2015, 98, 390-398. [CrossRef]

38. Hamad, H.; Bailón-García, E.; Morales-Torres, S.; Carrasco-Marín, F.; Pérez-Cadenas, A.; Maldonado-Hódar, F. Physicochemical properties of new cellulose- $\mathrm{TiO}_{2}$ composites for the removal of water pollutants: Developing specific interactions and performances by cellulose functionalization. J. Environ. Chem. Eng. 2018, 6, 5032-5041. [CrossRef]

39. World Health Organization. Water Quality and Health-Review of Turbidity: Information for Regulators and Water Suppliers (No. WHO/FWC/WSH/17.01); World Health Organization: Geneva, Switzerland, 2017.

40. Domínguez, A.; Couto, S.R.; Sanroman, M.A. Dye decolorization by Trametes hirsuta immobilized into alginate beads. World J. Microbiol. Biotechnol. 2005, 21, 405-409. [CrossRef]

41. Astuti, N.; Wibowo, N.; Ayub, M.R.S.S.N. The porosity calculation of various types of paper using image analysis. J. Pendidik. Fisika Indones. 2018, 14, 46-51. [CrossRef]

42. Technical Association of the Pulp Paper (TAPPI). Industry TAPPI Test Methods; TAPPI: Atlanta, GA, USA, 1988. 